\title{
Desafios da Inovação Tecnológica para a Sustentabilidade Intergeracional
}

\section{Challenges of Technological Innovation for Intergenerational Sustainability}

Salete Oro Boff ${ }^{1}$

${ }^{1}$ Faculdade Meridional, Passo Grande, RS, Brasil

Resumo: A inovação tecnológica causa inquietações entre preservar os valores de sustentabilidade ou atender à pressão de agentes econômicos pela exploração do "novo". Com esses pressupostos, utilizando-se o método dedutivo, serão analisados os desafios da inovação tecnológica para a sustentabilidade intergeracional. Considera-se que esses temas estão relacionados a valores e a direitos fundamentais do ser humano que superam as percepções do presente, envolvendo a responsabilidade com as futuras gerações.

Palavras-chave: Sustentabilidade. Inovação Tecnológica. Direitos Fundamentais.

\begin{abstract}
Technological innovation causes concerns between preserving sustainability values or meeting pressure from economic agents to exploit the 'new'. Using these assumptions, using the deductive method, we analyze the challenges of technological innovation for intergenerational sustainability. These themes are considered to be related to values and fundamental rights of the human being, which surpass the perceptions of the present, involving the responsibility for future generations.
\end{abstract}

Keywords: Sustainability. Technological Innovation. Fundamental Rights.

\section{Introdução}

As relações entre ciência, tecnologia e economia estão cada vez mais próximas, com destaque à pressão pela obtenção de resultados econômicos nos investimentos em inovação tecnológica. Essa predominância da visão econômica traz inquietações, não só entre os cidadãos, mas

Recebido em: 08/08/2017

Revisado em: 03/10/2018

Aprovado em: 23/09/2019 
também entre os cientistas, que, especializados, não possuem o domínio sobre todo o saber produzido.

Mesmo reconhecendo que os avanços do conhecimento nas áreas de ciência e tecnologia a justifica pela busca incessante de inovações com resultado benéfico para o ser humano, parte-se do pressuposto de que o desenvolvimento tecnológico traz implícito o bem-estar da sociedade. Entretanto, a ciência não é neutra e no seu desenvolvimento podem estar implicados interesses de várias ordens, eliminando o seu caráter primordial, do mesmo modo que os resultados das inovações podem ficar aquém dos desejados.

Desse modo, surge a indagação de como proceder frente ao desenvolvimento da ciência, evitando que o debate se reduza e reproduza a garantia de vantagens econômicas, em detrimento de valores essenciais da espécie humana para a sustentabilidade intergeracional.

Utilizando-se o método dedutivo, inicialmente contextualiza-se a evolução da ciência e da técnica com embasamento teórico para, na sequência, apresentar possibilidades de superação de desafios da inovação tecnológica sustentável para a presente e futuras gerações.

\section{Evolução da Ciência e das Concepções da Técnica ${ }^{1}$}

A evolução da técnica e a sua cientificação levaram à transformação do trabalho, da vida social, do tempo livre e de quase todos os aspectos da cultura. O meio natural gradativamente foi substituído pelo meio técnico, assumindo a técnica um papel indispensável na civilização, gerando a exigência de regulação e direcionamento de sua existência. Chega-se a considerar a técnica, em vezes, como elemento invisível em relação ao resultado produzido, originando um embate com a teoria de Bacon (1999), desafiando a reflexão e compreensão do fenômeno novo, vez que há uma maquinação da ciência e da técnica² . Nesse sentido, a técnica há de ser

\footnotetext{
${ }^{1}$ Veja-se sobre a temática Boff (2010).

${ }^{2}$ Nesse sentido, exemplificam as crises dos sistemas ecológicos e a prática da engenharia genética.
} 
pensada e gerida além da ideia da concepção da tecnologia como simples ciência aplicada. Na linha do "mito da neutralidade científica" não é igualmente possível prosseguir na atitude ingênua de ignorar os desafios éticos da moderna tecnologia. Ao contrário, torna-se imprescindível ultrapassar a concepção antropológica (unilateral) e encarar a técnica numa visão global e relacionada a aspectos epistemológicos, éticos, culturais, sociais e metafísicos, com um complemento recíproco entre a análise sistemática e a histórica.

Esse impulso gerado pela revolução científica implica numa completa reconstrução das categorias do pensamento, de construção de uma sociedade mais humana, com a possibilidade teórica de intervir diretamente na natureza e nasce o desejo pragmático de controlá-la:

[...] que comporta uma nova definição do conhecimento, que já não é contemplação, mas utilização, uma nova atitude do homem perante a natureza: ele deixa de olhá-la como uma criança olha a mãe, tomando-a por modelo; quer conquistá-la, tornar-se 'dono e senhor' dela. (LENOBLE, 1990, p. 270)

Autores, como Morin (1984) e Santos (1987), acreditam que o século XX teria inaugurado um período de crise no paradigma científico moderno, em razão de tratar-se de um momento histórico que exige uma radical e profunda reforma no pensamento científico, que logre superar todas as formas de reducionismo. São visíveis os descontroles resultados das tecnologias, presentes em várias manifestações como na poluição, no esgotamento progressivo de recursos naturais não renováveis, na superpopulação do planeta e na ampliação das diferenças de poder entre classes sociais, assim como no distanciamento que se estabelece entre as nações centrais e periféricas.

Marcadamente essas mudanças surgiram no final do século XIX, com descobertas que vem romper com o paradigma mecanicista, como a Teoria da Evolução por Seleção Natural de Darwin (2007), publicada em 1859, cujos conceitos centrais são a 'variação aleatória' e a 'seleção

${ }^{3}$ Sobre o assunto, ver Japiassu (1975). 
natural', que representam as pedras angulares de toda teoria evolucionista moderna. O que era concebido como previsível, passa a contrapor um conceito mais complexo de sistema em permanente mudança.

Seguem com a teoria da relatividade - no século XX, Popper e Kuhn. Para Popper o conhecimento científico tem que ser submetido a testes rigorosos e sistemáticos, cujo objetivo é a tentativa permanente de falseá-las. Desse modo, o conhecimento científico jamais poderia pretender à segurança de uma verdade absoluta acerca dos fenômenos do mundo. $\mathrm{O}$ conhecimento científico será o resultado de uma conjectura que resistiu a testes até aquele momento, portanto "[...] o que tentamos na ciência é descrever e (na medida do possível) explicar a realidade" (POPPER, 1973, p. 40).

Na centralidade da teoria de Popper está o 'problema da demarcação', entendido como delimitar uma área do discurso significativo para a ciência, distinguindo as teorias científicas da metafísica e/ou da falsa-ciência. De acordo com o filósofo, o sentido aparece sempre solidário da problematicidade que germina, sem exceção, por todas as áreas do conhecimento e da ação dos homens. Reformula-se o problema com o intuito de distinguir um método empírico de um método não empírico ou até pseudoempírico.

Assim, Popper estabelece como critérios para delimitar a cientificidade de uma teoria, a possibilidade de refutação, pois a irrefutabilidade não é uma virtude, mas sim um vício. Nessa linha, os testes constituem tentativa para refutar uma teoria e estas podem ser mais testáveis e, por isso, estão mais expostas à refutação. O critério de refutabilidade não consiste num critério de sentido ou significação, mas sim no traçar de uma linha divisória entre o discurso científico e outros tipos de conhecimento. A submissão de um tipo de conhecimento a constantes testes garante que, ao menos tendencialmente, aproximam-se da verdade (verdade provisória), por meio da eliminação das teorias falsas.

Uma abordagem diversa é a proposta de Kuhn (1996) assentada na ideia de que a prática dos cientistas não se adapta à proposta popperiana de uma permanente tentativa de falseamento das teorias vigentes. Segundo o autor, o mais característico da ciência 'normal' seria o trabalho 
de confirmação do paradigma dominante, com os cientistas procurando articular sua estrutura e ampliar os limites de sua aplicabilidade. Nessa perspectiva, a história da ciência não pode ser uma história de progresso rumo a uma verdade objetiva. É antes um avanço, de mudanças radicais e incompatíveis de visão, de maneira que a aspiração a descrever cada vez melhor a realidade torna-se duvidosa.

Com essa postura, Kuhn (1996) é considerado como inovador. Seus estudos direcionam-se para mostrar o contraste entre duas concepções da ciência: na primeira concepção a ciência é entendida como uma atividade completamente racional e controlada (formalista); na segunda, considera a ciência como uma atividade concreta, construída ao longo do tempo e que, em cada época histórica, apresenta peculiaridades e características próprias (historicista).

Na obra A Estrutura das Revoluções Científicas, a presença de uma crise daria origem à "revolução". A emergência de novas teorias é geralmente precedida por um período de insegurança profissional pronunciada, pois exige a destruição em larga escala de paradigmas e grandes alterações nos problemas e técnicas da ciência normal. A insegurança provém do "[...] fracasso constante dos quebra-cabeças da ciência normal em produzir os resultados esperados. O fracasso das regras existentes é o prelúdio para uma busca de novas regras." (KUHN, 1996, p. 95). Frente à impossibilidade de solução dos problemas com a utilização das regras existentes, os cientistas questionam constantemente os princípios da ciência que praticam seu trabalho, passando a adaptar as regras e a transformá-las em novas teorias que possam resolver a crise. O fracasso de um paradigma em resolver determinados problemas é momento oportuno para que surjam novas soluções. Exemplifica:

Na manufatura, como na ciência a produção de novos instrumentos é uma extravagância reservada para as ocasiões que o exigem. O significado das crises consiste exatamente no fato de que indicam que é chegada a ocasião para renovar os instrumentos. (KUHN, 1996, 105) 
Kuhn apresenta a noção de paradigma como algo que circunscreve o que o cientista observa e problematiza. Compreende a prática e o desenvolvimento científico como equivalente ao de qualquer outra instituição social, isto é, como fruto de negociações e acordos entre grupos. "Se a ciência é a reunião de fatos, teorias e métodos reunidos nos textos atuais, então os cientistas são homens que, com ou sem sucesso, empenharam se em contribuir com um outro elemento para essa constelação específica." (KUHN, 2006, p. 20). E, acrescenta que o desenvolvimento "[...] torna-se o processo gradativo através do qual esses itens foram adicionados, isoladamente ou em combinação, ao estoque sempre crescente que constitui o conhecimento e a técnica científica.” (KUHN, 2006, p. 20).

Já para Marcuse (1982), a racionalidade científica moderna é intrinsecamente instrumental, ou seja, que a alegada "neutralidade" da metodologia científica estaria, em realidade, a serviço de um objetivo bem específico - o domínio da natureza. Por outro, mostra que essa racionalidade científica instrumental é também responsável via tecnologia, pela dominação política. A técnica aparece aqui repetidamente como a manifestação prática da razão instrumental.

A máquina é indiferente aos usos sociais que lhe são dados, desde que tais usos permaneçam dentro de suas possibilidades técnicas [...] a dominação se perpetua e se estende não apenas através da tecnologia, mas como tecnologia, e esta garante a grande legitimação do crescente poder político que absorve todas as esferas da cultura. (MARCUSE, 1982, p. 153)

Merecem destaque as ideias de Habermas (1983), ele explicita o vínculo entre a ciência e o domínio sobre a natureza, formula a tese de que, por detrás do desenvolvimento de cada uma das áreas de conhecimento, existe um interesse correspondente: interesse por controlar o meio. O desenvolvimento científico, desde seu início, teria sido norteado pelo interesse de manipulação técnica da natureza, com vistas à libertação da coação que tal atitude sempre exerceu sobre a humanidade.

Na obra Técnica e Ciência enquanto Ideologia (HABERMAS, 1983), o filósofo apresenta a união entre conhecimento e interesse como 
desencadeadoras de um processo de racionalização crescente, tanto sobre o indivíduo tomado isoladamente, quanto sobre a sociedade.

Pode-se referir, ainda, a teoria de Weber (2001) sobre a racionalidade e suas relações com os sistemas científico-tecnológicos das sociedades modernas. A racionalização (entendida como a regularização da ação humana na busca por determinados fins) presente no âmbito econômico é igualmente produto da especialização científica e da dominação técnica, peculiares à civilização ocidental, que, historicamente se desenvolvem mesmo antes do próprio capitalismo.

Para o autor, o conceito de "racionalização" se desenvolveu principalmente pelas ciências ocidentais em suas possibilidades técnicas. "Essa racionalização intelectualista [...] devemos à ciência e à técnica-científica [...]" (WEBER, 2001, p. 30), pois ela é fundamentada em princípios racionais e no método científico a partir da concepção do Ocidente. Assim, a racionalização não está para o progresso do saber humano no sentido de um melhor conhecimento de suas condições de vida, mas de forma oposta: constitui-se em distanciamento do homem no que concerne aos conhecimentos mínimos de funcionamento da civilização científico-tecnológica. A grande consequência da racionalidade instrumental foi à perda da autonomia do indivíduo e a ruptura da situação. $\mathrm{O}$ aparato produtivo e as mercadorias se impõem ao sistema social como um todo. A burocracia retrata o processo de racionalização crescente a que foi submetida à sociedade ocidental moderna, e esse processo, por sua vez, com a mecanização e a rotinização opressivas impostas aos seres humanos.

Diante do exposto sobre a evolução da técnica, pode-se constatar a existência de duas tradições de pensamento, uma que enfatiza a busca de um entendimento matemático do mundo e a segunda fundada na necessidade de realização de experimentos e na aplicabilidade prática. Essas tradições vão dar o sentido da busca do conhecimento pelo conhecimento à ciência moderna, cuja finalidade está associada ao poder que este último pode trazer sobre as coisas, bem como sobre os próprios homens.

Vale destacar os rumos tomados pelo desenvolvimento da ciência e da tecnologia nas sociedades modernas, que ultrapassam a lógica objetiva de um sistema linear, apresentando-se como um sistema de interações 
mútuas, construídos e embasados no meio social, que recusam a ideia de ciência como compreensão neutra dos fenômenos do mundo, sem a influência de valores sociais, econômicos, culturais e os interesses políticos.

Há que se acrescentar, ainda, os possíveis riscos em relação aos aspectos pragmáticos da questão, e o descontrole das consequências negativas desencadeadas com o aumento do domínio tecnológico sobre a natureza. Particularmente, destaca-se o ritmo acelerado de degradação do meio ambiente, e que nem sempre o avanço das inovações tecnológicas serve ao bem-estar dos seres humanos em geral e a uma sociedade justa. Nesse campo, são relevantes as contribuições de Beck e Giddens (1997), que destacam os riscos ambientais e tecnológicos, como um dos aspectos negativos no desenvolvimento da ciência. O "risco" passa a configurar aspecto central da sociedade, para além da mera consideração como efeito colateral do progresso.

Com esse resgate da evolução da ciência e das concepções da técnica, tem-se claro que os avanços do conhecimento científico em si são insuficientes para atingir o projeto de desenvolvimento concebido a partir de um conceito amplo, no campo social, econômico, humano, cultural e ético, enfim sustentável. As pesquisas recentes, na área nuclear, na genética, apontam juntamente riscos da ciência, convocando a sociedade a debater suas orientações e suas aplicações, bem como implementar controles baseados na ponderação, na beneficência, na justiça, na ética da responsabilidade.

\section{Inovação Tecnológica Sustentável no Plano Intergeracional}

A inovação tecnologia resulta da ação de seus criadores e operadores, contempla a totalidade do homem, seus sentimentos, seus desejos e seu destino. Jonas (1997, p. 16) distingue três aspectos dessa tecnologia: a sua dinâmica formal, o seu conteúdo substancial e a ética. A dinâmica formal representa um processo contínuo que avança por meio de leis próprias. Enquanto a técnica pré-moderna desenvolvia-se de forma lenta, baseada na utilização de meios para o aperfeiçoamento e para a fabricação repetitiva, com fins reconhecidos e meios apropriados, a técnica moderna, 
em cada nova etapa exitosa, conduz a outros passos em todas as direções possíveis: “[...] el mero 'motivo' se convierte en causa forzosa en cada paso maior o 'importante' e cada inovação [...] esta segura de difundir-se com rapidez por la comunidad tecnologica.” (JONAS, 1997, p. 18). Assim, objetivos conhecidos podem aspirar a novas técnicas, como também novas técnicas podem almejar objetivos não conjeturados antes. Portanto,

[...] el 'progreso' no es un adorno de la moderna tecnologia ni tampoco una mera opción ofrecida por ella, que podemos ejercer si queremos, sino un impulso inserto em ella misma que, más allá de nuestra voluntad, repercute em el automatismo formal de sus modus operandi y em su oposición com la sociedad que lo disfruta [...]. (JONAS, 1997, p. 20)

No conteúdo substancial da técnica moderna, o autor evidencia o relacionamento da tecnologia com o homem e as suas possíveis consequências, as novas formas de poder e os objetivos que interferirão na atuação da conduta humana. Aponta a Revolução Industrial como marco da mecânica, da fabricação de máquinas para diversos fins, que formaram a cadeia produtiva. Em seguida, desenvolve-se o setor químico, com a transformação de substâncias sintéticas, as quais passam a substituir as substâncias naturais (a lã e o algodão dão lugar a fibras sintéticas). Após, surge a técnica de informação e a eletricidade, com a transmissão, a transformação e a distribuição de energia elétrica. Uma nova fase é marcada pela biologia molecular e pela manipulação genética, cujo objeto é o próprio homem. A biotecnologia cria a possibilidade "de reelaborar la constitución humana", de "pensar en la "imagem del hombre" e isso requer preparo das diversas áreas do conhecimento (JONAS, 1997, p. 16-31).

Aos aspectos formal e substancial, Jonas (1997, p. 33-34) associa a ética a uma exigência da responsabilidade humana, uma vez que a "[...] técnica es um ejercicio del poder humano, es decir, uma forma de actuación, y toda actuación humana está expuesta a su examen moral". Para tanto, o autor apresenta razões que demonstram a necessidade de considerar a ética no desenvolvimento da técnica. A primeira é a 'ambivalência dos efeitos' que tanto podem ser bons ou negativos; “[...] el presupuesto para 
ello es que la ética pueda distinguir claramente entre ambos usos, entre el uso correcto y el errôneo de una y la misma capacidade [...]"; a segunda é a 'automaticidade da aplicação' da ética à atividade permanente da técnica e a terceira razão é a dimensão global do espaço e do tempo (ao uso em 'escala global'), com repercussões presentes e nas gerações futuras. A responsabilidade do homem, diante de todos os seres vivos, situa-se 'além do antropocentrismo' e terá que considerar

[...] en su recién evelada vulnerabilidad frente a las excesivas intervenciones del hombre, su cuota en la atención que merece todo lo que tiene su respeto humano, es decir: todo lo vivo. [...] Como poder planetário de primer orden, ya no puede pensar solo en si mismo. (JONAS, 1997, p. 36)

Enquanto a técnica amplia o poder do homem sobre a natureza, há que se avaliar o quanto se pode ariscar nas grandes apostas técnicas, analisando os efeitos gerados: "Solo puede caminar hacia adelante, y tiene que obtener de la técnica misma, com uma dosis de moral moderadora, la medicina para su enfermedad. Éste es el eje de una ética de la técnica." (JONAS, 1997, p. 38-39).

Assim, até o momento que a técnica (PESSINI, 2000, p. 122) utilizava material inanimado (física e mecânica) era considerada inofensiva. A partir do instante que passa a fazer uso de organismos vivos, indaga-se sobre a liberdade (os limites) de investigação dessa matéria. Na técnica biológica "[...] el hombre puede ser objetivo directo de su propia arquitectura, y ello en su constitución física heredada" (JONAS, 1997, p. 110). Além disso, o desenvolvimento dessa técnica aumenta o poder do homem sobre a natureza, o poder do homem sobre o homem e a submissão do homem ao poder de outros. Na biologia, a complexidade apresenta-se nos fatores desconhecidos e nos resultados imprevistos e os objetos são originais: "Lo que hay entre el comienzo y el fin definitivo del experimento es la vida real de indivíduos y quizá de poblaciones enteras" e processos irreversíveis. Quanto a técnica biológica passa a interferir em outros setores e os seus resultados (“ambíguos") refletem-se em nível global. Estão incluídas, nesse campo, as pesquisas biomédicas que envolvem a inves- 
tigação de DNA recombinante, nas quais o produto pode "[...] conducir a realidades definitivas que se emancipen de la mano de su creador para ganar literalmente vida propia" (JONAS, 1997, p. 65-72). O processo de conhecimento converte-se em ação, dando surgimento a um novo ser autônomo, autoreprodutivo e interativo. Como expõe Jonas, a ciência pura (teoria) e a aplicada (prática) fundem-se no processo investigador e a proteção do bem público é condição sine qua non do investigador (JONAS, 1997, p. 74). Desse modo, para o desenvolvimento de pesquisas nessa área biotecnológica, é necessário considerar basicamente:

1.El objetivo de la investigación es práctico desde el principio, a saber: desarrollar una capacidad para la fabricación de algo que podría ser utili para la medicina, la agricultura y otras cosas, surgiendo el eventual benefício para la teoria como un efecto secundário del êxito práctico.

2.El método de la investigación, es decir el camino al conocimiento, es la produccción de hecho de las entidades mismas de las quê se busca el conocimiento y cuya utilidad há de ser puesta a prueba.

3.Las entidades así producidas dentro del contexto investigador no son inertes y activas tan solo por nueva mediación humana, sino vivas, es decir, activas por si mismas, de forma que potencialmente pueden producir por si mismas su ingreso em la esfera práctica, en el mundo exterior, y quitarnos de las manos la decisión sobre su uso o no uso.

4.La eventualidad, que teoricamente no se puede exluir, de recombinaciones genéticas de células germinales humanas (gametos o cigotos), a las que permita después llegar a término, las 'quimeras'resultantes em el fenótipo ya em el primer acto experimental 'logado'representarían, aunque no pasaran de ahí, actos últimos que dejan a sus espaldas toda teoria no vinculante. (JONAS, 1997, p. 72)

Ademais, a imprevisibilidade da técnica leva a questionar quais serão os valores da sociedade no futuro. Uma das virtudes a observar é a cautela diante "de la incertidumbre: in dúbio pro malo" (JONAS, 1997, p. 47-49) e a outra é ter presente o princípio da responsabilidade com fundamento na humanidade. Igualmente, é imperioso avaliar a possibilidade 
de atingir os objetivos da pesquisa com a utilização de outros métodos e materiais, sem fazer uso direto da manipulação de material humano, mesmo que os resultados pretendidos sejam obtidos de forma mais lenta.

Nessa senda, mister ter presente a relação cada vez mais próxima entre tecnologia, economia e poder, com destaque à pressão pela obtenção de resultados econômicos nos investimentos em tecnologia. Essa predominância da visão econômica traz inquietações no mundo jurídico. Assim, “[...] o novo saber é depositado nos bancos de dados e usado de acordo com os meios e segundo as decisões dos que detêm o poder. Há um verdadeiro desapossamento cognitivo, não só entre os cidadãos, mas também entre os cientistas" (PESSINI, 2000, p. 128). O conhecimento científico "[...] escapa das mãos de seu iniciador, e entram em jogo as múltiplas interações próprias da sociedade [...]", chegando, às vezes, a um "[...] destino oposto ao que era buscado inicialmente." (PESSINI, 2000, p. 128).

Com viés ao encontro da não neutralidade científica, Moser (2004, p. 112-113 $)^{4}$ expõe que os "[...] cientistas não são seres abstratos: nascem e vivem dentro de um contexto político, cultural e religioso. [...] A luta pelo poder é cada vez mais a luta pela distribuição e pelo acesso ou negação de conhecimentos, sobretudo na área da biotecnologia". Desse modo, num contexto contemporâneo, a pergunta kantiana: "O que posso saber?" Deve conter a questão: "O que posso fazer ou o que posso fabricar?” (MOSER, 2004, p. 129)5. Daí a certeza de que é necessário existir uma orientação ética no desenvolvimento das pesquisas científicas, com objetivo de conciliar o progresso técnico com os valores consagrados na sociedade, construindo uma ciência comprometida com a verdade do conhecimento e com a existência individual e social.

Isso será possível na medida que o homem se impor sobre esse novo poder, mantendo sua autonomia, sob a orientação de um imperativo ético novo, "un imperativo incondicional, fundamentado ontologicamente", dirigido ao agir coletivo que afeta toda a humanidade. Esse imperativo poderia se expressar de duas formas:

\footnotetext{
${ }^{4} \mathrm{O}$ autor remete à leitura da obra de Maia (2004, p. 128-129).

${ }^{5}$ No mesmo sentido é a posição de Gilbert Hottois (1990, p. 89).
} 
Obra de tal manera que los efectos de tua acción no sean destructivos para la futura posibilidad de una vida humana auténtica em la Tierra. $\mathrm{O}$ estas dos formulaciones positivas: Incluye em tu elección actual, como objeto también de tu querer, la futura integridad del hombre: o bien: Obra de tal manera que los efectos de tu acción sean compatibles com la permanência de una vida humana auténtica em la Tierra. (JONAS, 1995, p. 9-10 e 36)

Esse novo imperativo traz implícita a responsabilidade do homem no desenvolvimento da tecnologia, considerando a convivência com resultados imprevistos. Somente a participação criativa no progresso, com a ampliação da presença de especialistas nas diversas áreas e o envolvimento da sociedade, poderá estabelecer limites ao incremento tecnológico baseado em comportamentos éticos e valores que garantam um futuro à humanidade.

Para Habermas (1980, p. 318), o progresso técnico-científico contém um projeto de dominação, representa uma ideologia da sociedade industrial avançada, que substitui e paralisa as necessidades de emancipação. Conforme esse filósofo, os padrões do agir instrumental 'colonizam' as demais esferas da vida social, não só pela circunstância singular de o capitalismo ser um sistema fundado na economia, como também pelo lugar definitivo ocupado pela apologia da técnica e da ciência no universo dos valores e das normas éticas e morais.

Com esse destaque, Habermas (1980, p. 58) posiciona a ciência e a tecnologia como parte de um mesmo fenômeno social de dominação, por meio do controle da natureza, estendido ao homem. Nesse sentido, a tecnologia promove a grande racionalização da falta de liberdade do homem e demonstra a impossibilidade técnica de ser ele autônomo e de determinar a sua própria vida. A falta de liberdade aparece como uma submissão ao aparato técnico, que amplia as comodidades da vida e aumenta a produtividade do trabalho. Desse modo, a racionalidade tecnológica protege (em vez de suprimir) a legitimidade da dominação, e o horizonte instrumentalista da razão abre-se sobre uma sociedade racionalmente totalitária (HABERMAS, 1980, p. 58). 
A racionalidade da ciência e da técnica já é, de modo imanente, uma racionalidade de manipulação, de dominação (HABERMAS, 1994, p. 64 e ss.). Caracteriza-se por um crescente potencial de forças produtivas excedentes constituindo como sempre uma ameaça para o marco institucional, podendo também representar a legitimação das relações de produção. Portanto, não se pode partir da inocência da ciência. E mais, o universo tecnológico

[...] es 'como tal' indiferente frente a los fines políticos - puede servir de acelerador o de freno a una sociedad. Una calculadora electrónica puede servir lo mismo a un régime socialista que a un régime capitalista; un ciclotrón puede ser un buen instrumento, lo mismo para una guerra que para un partido pacifista (HABERMAS, 1999, p. 64) ${ }^{6}$

Sobre o tema, são representativas as considerações de Jonas (1995, p. 271-272): “[...] la ciência, que se há convertido em su hermana gemela - em que el 'progreso' como tal, em si automovimiento, es um hecho indudable, em el sentido de que cada etapa es necesariamente superior a la anterior."

$\mathrm{Na}$ visão de Capra (1982, p. 41) ${ }^{7}$, a tecnologia “[...] tem por meta o controle, a produção em massa e a padronização, e está sujeita, a maior parte do tempo, a uma administração centralizada que busca a ilusão de um crescimento ilimitado". Muitos defendem o desenvolvimento de novas técnicas, mesmo sem ter clareza sobre as consequências que podem surgir. Como bem assinala Jonas (1995, p. 272), a técnica modifica o mundo e determina as formas e condições reais de vida humana: a ambivalência presente aponta para a transformação dos hábitos e condições de

\footnotetext{
${ }^{6}$ Nesse sentido: "Hasta fines del siglo XIX no se registra una interdependencia de ciencia y técnica. Hasta entonces la ciencia moderna no contribuyó a la aceleración del desarrollo técnico y, por tanto, tampoco a la presión racionalizadora que ejerce desde abajo. [...] A mi juicio, la tesis fundamental de Marcuse de que la ciencia y la técnica cumplen también hoy funciones de legitimación del dominio nos proporciona la clave para analizar esa nueva constelación." (HABERMAS, 1999, p. 64).

${ }^{7}$ Essa concepção apoia-se na teoria darwinista, do século XIX, que julga ser a vida em sociedade uma constante luta pela existência (CAPRA, 1982, p. 41-42).
} 
vida pela técnica. $\mathrm{O}$ homem perde autonomia em função da pressão fática e psicológica da ordem tecnológica sobre as massas. Em vista disso, os riscos globais não podem mais ser considerados em termos de responsabilidade individual, como nas questões relacionadas com a manipulação genética, com o meio ambiente e, sim, como questões universais, cujo efeito provém das ações humanas, "mediadas pelas ciências, situam-se, em grande parte, no âmbito dos interesses vitais comuns da humanidade: pela primeira vez na história do gênero humano os seres são chamados a assumir, em escala planetária, a tarefa de uma responsabilidade solidária pelos efeitos de suas ações (OLIVEIRA, 2001, p. 175).

Tomando-se a responsabilidade como própria do ser humano, demonstrada pela capacidade de escolha entre alternativas de ação e pela avaliação dos resultados que possam causar em outros seres, percebe-se que a responsabilidade está para o "ser" que "é algo portador de valor" e o valor constitui um direito em relação às ações. Nessa concepção, a responsabilidade é entendida como "[...] a mediação entre os dois pólos constitutivos de toda ação: a liberdade e o caráter valorativo do ser." (OLIVEIRA, 2001, p. 2004).

Transpostas essas considerações na área do desenvolvimento da engenharia genética, constata-se o surpreendente emprego da técnica, acompanhado de incertezas, sem que os cientistas tenham condições de esclarecer os propósitos seguros de suas descobertas e procedimentos, nem tão pouco se um dia serão seguros. Os cientistas são pessoas humanas, envolvidos na sociedade e podem cometer equívocos, como qualquer humano. Ou seja, os avanços na biotecnologia deverão ser incentivados e protegidos, ultrapassando os modelos clássicos, das abordagens mecanicista e reducionista, com a adoção de "enfoques holísticos e ecológicos" dos cientistas (CAPRA, 1982, p. 46).

Afora essas inquietações dos avanços da ciência, outra questão presente é que os resultados não estão disponíveis a todos. $\mathrm{Na}$ verdade, verifica-se o aumento da distância entre os que possuem acesso às inovações e os que permanecem à margem do progresso, pois os benefícios oriundos das inovações são acessíveis a altos custos, portanto a uma camada de "privilegiados" economicamente. E, nesse ponto, como observa 
Moser (2004, p. 426), “[...] quando a biotecnologia se coloca ao serviço dos ricos e poderosos ela acaba se desvirtuando na sua própria razão de ser. Para estes, tudo; para os bilhões de famintos, nem os mais cotidianos cuidados e a satisfação das necessidades mais imediatas”.

Pode-se acrescentar, ainda, o fato de que as pesquisas na área da biotecnologia, inicialmente ligadas e mantidas pelo poder público, proliferaram nas empresas privadas, com grande aporte de recursos, visando desenvolver e obter produtos novos. A falta de investimentos estatais nas universidades e nas instituições pesquisadoras, principalmente em países em desenvolvimento, resulta na exportação de "cérebros privilegiados" para empresas privadas ou para países desenvolvidos, capazes de oferecer as condições necessárias para o desenvolvimento de suas pesquisas e garantir a proteção de privilégios pelo Estado onde estão localizadas.

Por certo, os resultados da implementação da biotecnologia repercutem diretamente na economia e garantem a competitividade internacional. Um exemplo disso acontece no setor da alimentação, com o desenvolvimento de sistema de diagnóstico e bioconservação de produtos fermentados, enzimas e leveduras híbridas. Existem, ainda, variedades modificadas geneticamente - tomates, batatas, algodão, soja, tabaco, entre outras - que apresentam resistência a herbicidas, a vírus e a insetos. Particularmente na medicina, a biotecnologia está revolucionando os métodos terapêuticos de tratamento das enfermidades hereditárias. Alguns produtos, como a insulina humana, representaram o marco de uma nova geração de medicamentos naturais e artificiais.

$\mathrm{O}$ avanço na ciência dá impulso à necessidade de formas de proteção (patente ou outra) com o fim de abarcar as novas tecnologias. Para Jeremy Rifkin (1999, p. 9-10), a biotecnologia dá origem a uma nova matriz operacional, baseada na "[...] localização, manipulação e exploração de recursos genéticos pelos cientistas e empresas, na concessão de patentes de genes, linhas de células, tecido geneticamente desenvolvido, órgãos e organismos". Além disso, realiza um recenseamento da biosfera da Terra, mapeia "aproximadamente cem mil genes que compõem o genoma humano", utiliza o computador para "decifrar, trocar, catalogar e organizar in- 
formação genética", e, sugere para o futuro um novo modo de reorganizar a economia e a sociedade (RIFKIN, 1999, p. 9-10).

Então, ao que parece, o grande desafio é conciliar o desenvolvimento da ciência e da técnica com o embasamento ético e responsável, estabelecendo diretrizes básicas para o desenvolvimento da pesquisa. Para isso, o mote dos cientistas terá como referencial o ser humano e a satisfação das necessidades de todos, inclusive daquelas nações que não possuem os fundos, nem os conhecimentos necessários para participar dos grandes projetos científicos. Sem se esquecer de que a forma da utilização da técnica é que poderá ser o diferencial; portanto, as opções políticas e democráticas serão decisivas para traçar os caminhos da humanidade.

Vasques (2004, p. 509) apresenta a proposta habermasiana de uma "ética da espécie", a qual "[...] compromete o cidadão do commonsense como pessoa moral, participante em processos democráticos que conduzam a uma legislação legítima, pertinente e de acordo com prioridades, também em assuntos de bioética". Para o filósofo, à sociedade cabe decidir sobre questões de tamanha repercussão presente e futura, já que está em jogo o próprio destino da espécie, como em relação à clonagem humana. Nesse sentido,

[esse] modelo de argumentação moral não é somente um excelente recurso emancipatório diante das pretensões objetivantes de determinada engenharia genética, senão que neste novo confronto com o positivismo científico a ética discursiva fica afinada e ganha em profundidade, ao fortalecer a participação democrática e a legislação a partir da soberania popular: nem o filósofo, nem o cientista, nem o especialista, os cidadãos é que hão de ter a última razão. (VASQUES, 2004, p. 510)

E, nos casos de colisão de direitos fundamentais e de liberdade de investigação científica e tecnológica, a questão será analisada tendo presente que a liberdade científica não é absoluta e, ocorrendo conflitos entre direitos ou princípios fundamentais, deverá ser observado que nenhum avanço tecnológico, cuja invasão provoque lesão a direito fundamental, como a dignidade da pessoa humana, poderá ser amparado por um sistema basea- 
do no reconhecimento dos direitos humanos. Como define Sarlet (2002), a dignidade da pessoa garante o respeito do ser, independentemente das condições sociais e culturais a que esteja vinculado, "[...] a dignidade, sendo qualidade inerente à essência do ser humano, se constitui em bem jurídico absoluto, e, portanto, inalienável, irrenunciável e intangível [...]." (SARLET, 2002, p. 123).

\section{Conclusão}

A crítica contemporânea à ciência reconhece a existência de um vínculo entre o conhecimento de algo e o controle ou domínio daquilo que se passou a compreender. Na busca de alternativas possíveis, Habermas apresenta o resgate da racionalidade comunicativa, por meio da ampliação da função da linguagem enquanto instrumento na busca do entendimento e da interação humana. Sua proposta para uma sociedade emancipada passa, necessariamente, pela busca do consenso intersubjetivamente estabelecido, com base na comunicação.

É óbvio que os avanços tecnológicos gerarão ainda muita polêmica. As opiniões sobre o tema são dinâmicas, consideram o contexto e são influenciadas pela percepção dos riscos e das vantagens de sua aplicação. Algumas premissas são fundamentais nesse campo, como o desenvolvimento de uma comunicação eficaz entre a comunidade científica e a sociedade, a institucionalização de consultas formais com a sociedade (plebiscitos, referendos) e a garantir que os riscos (princípio da precaução/dever de vigilância) da biotecnologia tenham sido cuidadosamente avaliados.

Logo, trata-se de grandes opções sociais, oportunidade em que a discussão envolverá a sociedade no processo democrático e superará o espaço técnico. A nova ordem jurídica (novas categorias regulatórias) terá, então, como fundamento, os valores elaborados pela sustentabilidade, norteados na ética da responsabilidade.

O ponto de partida será um mínimo de consenso, o qual poderá ser obtido com acordos internacionais, que estabeleçam parâmetros para o desenvolvimento da ciência, a partir da formação de bases comuns orien- 
tadas nos direitos fundamentais e acessíveis à participação de todos os seres humanos. Assim, cabe à sociedade global estabelecer o limite de coexistência harmônica entre a proteção dos sujeitos submetidos à pesquisa e ao avanço científico, preservando a liberdade científica, sem radicalizá-la como imperativo tecnocientífico.

Superar lacunas da jurisdição, da participação e de incentivo são os motes presentes e futuros. Os desafios das políticas vão além do espaço nacional, são hoje globais, inseridos nas exigências do novo cenário político internacional. Propostas como diversificar a sustentabilidade econômica, por meio de investimentos em estrutura básica, na educação e na qualidade de vida, associadas ao incremento de investimentos em fontes renováveis e alternativas de energia, são meios de se efetivar os direitos sociais, econômicos e difusos, bem como de implementar a cautela e a responsabilidade da atual geração para com as necessidades das futuras gerações.

A sustentabilidade demanda ações capazes de transformar modelos tecnoeconômicos cartesianos em resoluções que promovam real qualidade de vida as atuais e futuras gerações. Para tanto, a capacidade criadora humana deverá mover-se no sentido de encontrar o equilíbrio entre o desenvolvimento tecnológico e a preservação da dignidade do ser humano em harmonia com a natureza e perpetuada no tempo.

\section{Referências}

ALEXY, Robert. Teoria de los derechos fundamentales. Trad. Ernesto Garzõn Valdés. Madrid: Centro de Estúdios Constitucionales, 1997. p. 89.

AMILS, Ricardo. Impacto de la biotecnologia en el médio ambiente. In: PALACIOS, Marcelo. Bioética. Llanera (Astúrias): Nobel, 2000. BACON, Francis. Novum Organum ou Verdadeiras Indicações Acerca da Interpretação da Natureza. Trad. e notas: José Aluysio Reis de Andrade [1999]. Disponível em: http://br.egroups.com/group/ acropolis. Acesso em: $1^{\circ}$ mar. 2010. 
BECK, Ulrich; GIDDENS, Anthony; LASH, Scott. Modernização reflexiva. São Paulo: Unesp, 1997.

BOFF, Salete Oro. A ciência e o desvelar da biotecnologia: a nova relação entre o homem, a técnica e o direito. In: REIS, Jorge Renato: LEAL, Rogerio Gesta. (org.). Direitos sociais \& políticas públicas. Santa Cruz do Sul, RS: EDUNISC, 2010. v. 10. p. 3.274-3.304.

BOFF, Salete Oro. Proteção jurídica das cultivares na UPOV, no TRIPs e os limites na legislação brasileira: o embate entre interesse público e privado. Anuário Mexicano de Derecho Internacional, [S.l.], v. XIX, p. 433-456, 2019.

BOFF, Salete Oro; MENEGAZZO, Andre F. Apontamentos sobre a Propriedade Intelectual e sustentabilidade: por num limite jurídico da inovação. Revista NOMOS, Fortaleza, v. 38, p. 19-40, 2018.

BOFF, Salete Oro; ZAMBAM, Neuro J. Razões que fundamentam o modelo de desenvolvimento sustentável na sociedade contemporânea.

Revista Brasileira de Estudos Políticos, [S.l.], v. 106, p. 108-129, 2012.

BOFF, Salete Oro; ZAMBAM, Neuro J. Os direitos fundamentais e o exercício das liberdades substantitvas. Jurispoiesis, Rio de Janeiro, v. 1, p. 355-372, 2012.

BOFF, Salete Oro; BORTOLANZA, Guilherme. A teoria da reconstrução do direito de habermas com foco no princípio da dignidade humana. Revista Jurídica CESUMAR do Mestrado, [S.l.], v. 11, p. 345-356, 2011.

BOFF, Salete Oro; FARIA, Josiane P. Conflitos sociais: igualdade e solidariedade para a reconciliação social. Revista do Direito, Santa Cruz do Sul, v. 36, p. 59-73, 2011.

BOFF, Salete Oro; FARIA, Josiane $\mathrm{P}$. O direito fundamental à tecnologia: algumas reflexões acerca do capital social, do desenvolvimento e da participação sócio-política. Revista de Direitos e Garantias Fundamentais (FDV), [S.l.], v. 9, p. 11-36, 2011.

BROWNE, J. A Origem das Espécies de Darwin: uma Biografia. Rio de Janeiro: Zahar, 2007. 
DESCARTES, René. Discurso do Método. Lisboa: Sá e Costa, 1980. $6^{\text {a }}$ parte. DOMINGUES, Douglas Gabriel. Privilégios de invenção, engenharia genética e biotecnologia. Rio de Janeiro: Forense, 1989.

FUKUYAMA, Francis. Nosso futuro pós- humano: conseqüências da revolução biotecnológica. Rio de Janeiro: Rocco, 2003.

FURTADO, Lucas Rocha. Sistema de propriedade industrial no direito brasileiro. Brasília, DF: Brasília Jurídica, 1996.

HABERMAS, Jürgen. Técnica e ciência enquanto "ideologia". São Paulo: Editora Abril, 1980. (Coleção Os pensadores).

HABERMAS, Jürgen. Conhecimento e interesse. São Paulo: Editora Abril, 1983. (Coleção Os Pensadores).

HABERMAS, Jürgen. Mudança Estrutural na Esfera Pública. Rio de Janeiro: Tempo Brasileiro, 1984.84.

HABERMAS, Jürgen. Teoria analítica da ciência e dialética. In.

BENJAMIN, Walter. Textos escolhidos: os pensadores. São Paulo:

Editora Abril, 1980. v. XLVIII.

HOTTOIS, Gilbert. O paradigma bioético. Trad. Paula Reis. Lisboa: Salamandra, 1990.

JAPIASSU, Hilton. O mito da neutralidade científica. Rio de Janeiro: Imago, 1975.

JONAS, Hans. El principio de responsabilidad. Trad. Javier M.

Fernandez Retenaga. Barcelona: Heder, 1995.

JONAS, Hans. Técnica, medicina y ética. Trad. Carlos Fortea Gil. Buenos Aires: Paidós, 1997.

KAUL, Inge; GRUNBERG, Isabelle; STERN, Marc A. Introdução. In: KAUL, Inge; GRUNBERG, Isabelle; STERN, Marc A. Bens Públicos Globais: cooperação internacional no século XXI. Rio de Janeiro: Record, 2012.

KUHN, Thomas. A Estrutura das Revoluções Científicas. Trad. Beatriz Vianna Boeira e Nelson Boeira. São Paulo: Perspectiva, 2006. 
LENOBLE, Robert. História da idéia de natureza. Lisboa: Edições 70, 1990.

LÉVI-STRAUSS, Claude. Antropologia estrutural. Tradução de Chaim Samuel Katz e Eginardo Pires. Rio de Janeiro: Tempo Brasileiro, 1975.

LÉVI-STRAUSS, Claude. O Pensamento selvagem. Tradução de Maria Celeste da Costa e Souza e Almir de Oliveira Aguiar. São Paulo. Editora: Nacional, 1976.

MAIA, Newton Freire. A ciência por dentro. Petrópolis: Vozes, 2004, p. $128-129$

MARCUSE, Herbert. A ideologia da sociedade industrial: o homem unidimensional. Rio de Janeiro: Zahar Editores, 1982.

MORIN, Edgar. Ciência com consciência. Lisboa: Publicações EuropaAmérica, 1984.

MOSER, Antônio. Biotecnologia e Bioética: para onde vamos?

Petrópolis: Vozes, 2004.

OLIVEIRA, Bernardo Jefferson de; CONDÉ, Mauro Lúcio Leitão.

Thomas Kuhn e a nova historiografia da ciência. [2010]. Disponível em: www.portal.fae.ufmg.br/seer/index.php/ensaio/article/.../48/79. Acesso em: 13 mar. 2010.

OLIVEIRA, Manfredo Araújo de. Desafios éticos da globalização. São Paulo: Paulinas, 2001. p. 175.

PESSINI, Leo; BARCHIFONTAINE, Christian de Paul de. Problemas atuais de Bioética. 5. ed. São Paulo: Loyola, 2000.

PIMENTEL, Luiz Otávio. Direito industrial: as funções do direito de patentes. Porto Alegre: Síntese, 1999.

POPPER, Karl. La Logica de la Investigación Científica. Trad. de V. Sanchez de Zavala. Madrid: Tecnos, 1973.

RIFKIN, Jeremy. O Século da biotecnologia. Trad. Arão Sapiro. São Paulo: Makron Books, 1999. 
ROSSI, Paolo. O nascimento da ciência moderna na Europa. São Paulo: EDUSC, 2001.

SANTOS, Boaventura de Souza. Um discurso sobre as ciências. Porto: Afrontamento, 1987.

SARLET, Ingo Wolfgang. Dignidade da pessoa humana e direitos fundamentais na Constituição Federal de 1988. 2. ed. Porto Alegre: Livraria do Advogado, 2002.

SCHOLZE, Simone H. C. Patentes, transgênicos e clonagem. Brasília, DF: UnB, 2002.

SERRA, Paulo. O devir e os limites da ciência. Coleção Lusofilosofia. Covilhã: Lusofilosofia, 2008.

TOURAINE, Alain. Crítica da modernidade. Petrópolis: Vozes, 1999.

VASQUES, Guilhermo Hoyos. Bioética e moral comunicativa. In. GARRAFA, Volnei; PESSINI, Leo. Bioética: poder e injustiça. São Paulo: Loyola, 2004. p. 509-516.

WEBER, Max. Ensaios de Sociologia. London: Routledge \& Kegan Paul Ltd., 1957.

WEBER, Max. A ética protestante e o espírito do capitalismo. São Paulo: Martin Claret, 2001.

Salete Oro Boff é docente do PPGDireito IMED - Faculdade Meridional, na linha de pesquisa "Mecanismos de Efetivação da Democracia e da Sustentabilidade". Pós-Doutora em Direito-UFSC. Doutora em Direito-UNISINOS. Pesquisadora Bolsista Produtividade em Pesquisa, CNPq.

E-mail: salete.oro.boff@gmail.com

Endereço Profissional: Rua Senador Pinheiro, 304 - Passo Fundo - RS. CEP: 99070-220. 